\title{
Stroke Burden and Services in the Philippines
}

\author{
Jose C. Navarro ${ }^{a}$ Narayanaswamy Venketasubramanian ${ }^{\text {b }}$ \\ a University of Santo Tomas Hospital, Jose R Reyes Medical Center, St Luke's Medical Center, Manila, Philippines; \\ ${ }^{\mathrm{b}}$ Raffles Neuroscience Centre, Raffles Hospital, Singapore, Singapore
}

There are limited data on the epidemiology of stroke in the Philippines, a problem common to many countries in Southeast Asia [1]. Lack of interest, incentives, training, and financial support among health workers are some of the reasons for this situation. In recent years, several hospital-based studies, 3 nationwide surveys, and 1 community-based study have been undertaken, but without reliable data being obtained on the incidence and overall burden of stroke. The Food and Nutrition Research Institute, the Department of Science and Technology, and the Department of Health, together with some medical societies, spearheaded national surveys in 1998, 2003 , and 2008. In the latest survey, which used structured questionnaires, 7,700 adults (aged $\geq 20$ years) underwent face-to-face interviews in a stratified multistage sampling design to determine the prevalence of cardiovascular risk factors, with the following results: hypertension $25 \%$, diabetes $4 \%$, dyslipidemia $72 \%$, smoking $31 \%$, and obesity 5\%. In the 2003 and 2008 national surveys, the unadjusted prevalence of stroke was $1.4 \%$ and $1.2 \%$, respectively [2].

From June to December 1999, a community-based survey of stroke was performed in a mixed rural/urban community $(n=36,800)$ located several hours drive south of the capital, Manila [3]. Using a multistage stratification

karger@karger.com www.karger.com/cee

Karger"
(C) 2021 The Author(s)

Published by S. Karger AG, Basel

This is an Open Access article licensed under the Creative Commons Attribution-NonCommercial-4.0 International License (CC BY-NC) (http://www.karger.com/Services/OpenAccessLicense), applicable to the online version of the article only. Usage and distribution for commercial purposes requires written permission. sampling design, the heads of households were interviewed by trained research staff using a questionnaire created by the Stroke Association in the Philippines. Individuals with suspected stroke were subsequently visited by a neurologist, but no neuroimaging was performed. Of a total of 19,113 participants, the overall prevalence of stroke was $486 / 100,000$ of the population, and $1.4 \%$ $(1,400 / 100,000$ of the population) in those aged $\geq 40$ years, which is similar to the outcomes of national surveys.

A study of stroke risk factors was performed using a multicenter, multiregional, 1:1 matched case-control study design across 55 tertiary hospitals in 13 of the 16 administrative regions of the Philippines [4]. Of a total of 961 patients with confirmed first-ever-stroke matched to 961 hospital-based stroke-free controls, the independent risk factors identified, i.e., hypertension, diabetes mellitus, atrial fibrillation, myocardial infarction, current smoking, habitual snoring, stress, and frequent alcohol consumption, were of a similar profile to developed countries.

Unfortunately, there are large discrepancies in the provision of stroke services between urban and rural areas of the Philippines, due, in part, to the maldistribution of specialists and those with adequate training in stroke. 


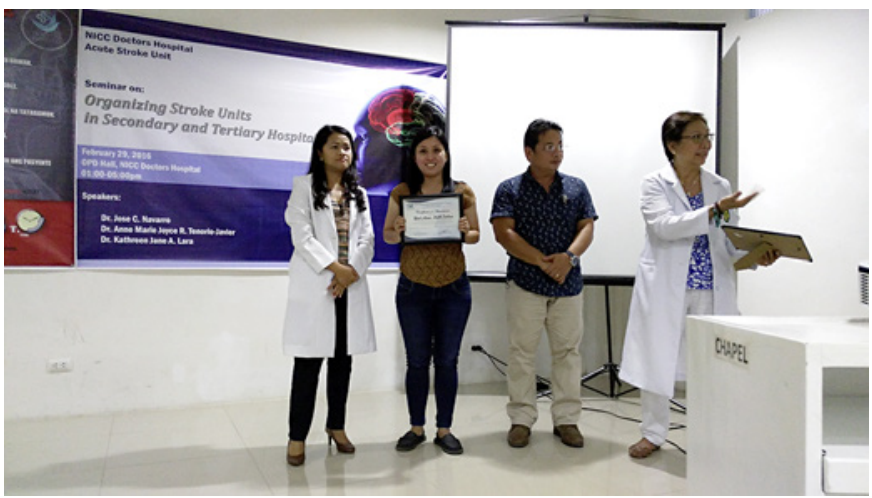

Fig. 1. A workshop seminar on the establishment of stroke units (permission was not needed for the publication of this photograph).

Diagnostic equipment is vital for stroke care but is very scarce in rural areas where there are only a few hospitals with established stroke units. The poor understanding of and poor efforts to adequately control cardiovascular risk factors contribute to high rates of stroke recurrence [5].

Following the introduction of national guidelines and care pathways, some hospitals have developed evidencebased approaches for the management of stroke patients. With the large efforts of the Stroke Society, the number of stroke units rose from 2 in 1999 to currently nearly 50 across the country (Fig. 1). This number is far short of the ideal recommended by the World Stroke Organization, and, as most of these units are located in metropolitan areas, they are not accessible to patients who live in remote areas. In 2020, stroke units at 11 institutions managed $>1,000$ patients with good outcomes [6].

Despite intravenous thrombolysis with recombinant tissue plasminogen activator being introduced in 1999 through a compassionate license being granted by the drug authorities, its use remains low due to limited medical training, the unavailability of stroke pathways, and, most importantly, the high out-of-pocket cost of this treatment to many patients. A multicenter experience of thrombolysis in 157 patients (approx. 1.4\% of all those with acute ischemic stroke) showed an inhospital mortality of $14.6 \%$ and total deaths of $18.3 \% ; 73.1 \%$ survived with a good outcome (a modified Rankin scale score of $0-2$ ) at 90 days. Symptomatic intracranial hemorrhage occurred in $12.1 \%$ [7]. While the frequency of intracranial hemorrhage appears higher than in international registries, the level of recovery appears comparable. There

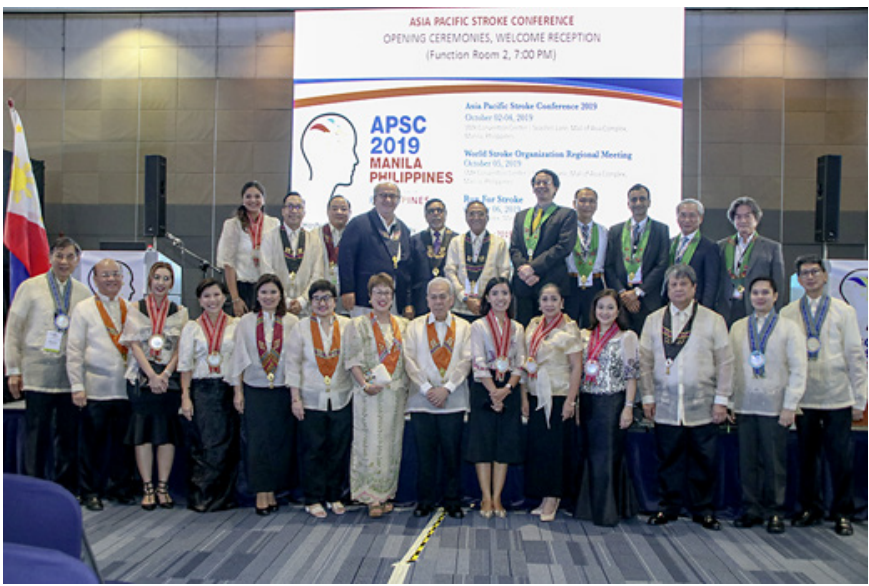

Fig. 2. Asia Pacific Stroke Conference 2019, Manila, Philippines (permission was not needed for the publication of this photograph).

are about 5 institutions offering mechanical thrombectomy, with few cases to date.

National stroke conferences have been held for the last 20 years and provide an opportunity for various healthcare professionals to enhance their stroke knowledge in the Philippines (Fig. 2). An administrative order for a national policy on stroke was recently signed by the Department of Health to further enhance skills, services, and projects, including the potential for a national stroke registry [8]. There is the likelihood that thrombolysis will receive government approval as a subsidized treatment. A hub-and-spoke system is being organized to support some unequipped and understaff hospitals around a tertiary stroke center. Following telemedicine, improved coordination of hub-and-spoke hospitals for decision-making would likely improve the efficiency and appropriateness of treatments.

Despite the many barriers to further advancing stroke services and research, there is good professional organizational and government support to carry out future programs. Dissemination of knowledge and the cooperation of health care workers are important aspects for ensuring appropriate implementation of stroke programs and related activities across this large, diverse, and resourcepoor country.

\section{Conflict of Interest Statement}

The authors have no conflicts of interest to declare. 


\section{Funding Sources}

There was no funding.

\section{Author Contributions}

J.C.N. conceptualized and wrote the paper and approved the final version.

N.V. conceptualized the paper, performed critical review, approved the final version, and formatted and submitted the paper.

\section{References}

1 Venketasubramanian N, Yoon BW, Pandian J, Navarro JC. Stroke Epidemiology in South, East, and South-East Asia: A Review. J Stroke. 2017 Sep;19(3):286-94.

2 Sy RG, Morales DD, Dans AL, Paz-Pacheco E, Punzalan FE, Abelardo NS, et al. Prevalence of atherosclerosis-related risk factors and diseases in the Philippines. J Epidemiol. 2012; 22(5):440-7.
3 Navarro JC. Prevalence of Stroke: community survey. Phil J Neurol. 2005;9:11-15.

4 Roxas A. The RIFASAF Project: a case-control study on risk factors for stroke among Filipinos. Phil J Neurol. 2002;6(1):1-7.

5 Buenaflor FG, Navarro JC, Lara KJ, Venketasubramanian N. Recurrence Rate of Ischemic Stroke: A Single Center Experience. Austin J Cerebrovasc Dis Stroke. 2017;4(2):1057.
6 Navarro JC, Escabillas C, Aquino A, Macrohon C, Belen A, Abbariao M, et al. Stroke units in the Philippines: an observational study. Int J Stroke. 2021. DOI: 10.1177/1747493020981730.

7 Navarro JC, San Jose MC, Collantes E, Macrohon-Valdez MC, Roxas A, Hiyadan J, et al. Stroke Thrombolysis in the Philippines. Neurol Asia. 2018;23(2):115-20.

8 Department of Health. Philippines. www. doh.gov.ph 